\title{
ГОСУДАРСТВЕННАЯ ПРОГРАММА И ПРОЕКТНЫЙ ПОДХОД В БЮДЖЕТНОМ ПЛАНИРОВАНИИ В РОССИЙСКОЙ ФЕДЕРАЦИИ
}

\author{
(c) 2019 Канкулова Маржинат Ильясовна \\ доктор экономический наук, профессор \\ Санкт-Петербургский государственный экономический университет, Россия, Санкт-Петербург
}

(c) 2019 Иванова Наталия Георгиевна

доктор экономический наук, профессор

Санкт-Петербургский государственный экономический университет, Россия, Санкт-Петербург

Эффективность системы управления государственными финансами страны характеризуется достигаемыми результатами в их соотношении с затратами. Современным методом бюджетного планирования, имеющим наибольший потенциал обеспечения эффективности использования государственных финансовых ресурсов, является программно-целевой метод, который имеет успешный опыт применения в мировой практике.

В настоящей статье подведены итоги исследования предпосылок внедрения, истории развития, современного состояния процессов бюджетного планирования, ориентированных на достижение наилучших результатов за счет выделенного объема средств или заданных результатов с минимальными затратами, в Российской Федерации. Изложены результаты анализа проблем и ограничений в обеспечении целевых параметров государственной политики посредством таких инструментов бюджетирования, как государственная программа и проектный подход в программном планировании. Сформулированы выводы о перспективах превращения государственных программ в эффективный инструмент проектной деятельности, формирующий условия для реализации национальных целей за счет полноценной интеграции стратегического целеполагания, бюджетного планирования и операционного управления.

Ключевые слова: Бюджетное планирование, бюджетный прогноз, государственная программа, проектный подход, приоритетный проект, национальный проект

В основу современной модели государственного регулирования социально-экономических процессов в Российской Федерации заложены принципы стратегического управления, подразумевающего определение приоритетов и реализацию мероприятий по достижению заданных результатов в определённой перспективе. Долгосрочный характер решений в этой области обеспечивается системой государственного стратегического планирования, в рамках которой формируются концептуальные и прогнозные документы, нормативные правовые, программные, планирующие и другие распорядительные акты, перечень и назначение которых регламентированы федеральным законом «О стратегическом планировании в Российской Федерации» от 28.06.2014 г. № 172-ФЗ. Устанавливая правовые основы стратегического планирования, указанный федеральный закон определяет его как деятельность по целеполаганию, прогнозированию, планированию и программированию органов власти и местного самоуправления, на- правленную на решение задач устойчивого социально-экономического развития Российской Федерации, субъектов Российской Федерации и муниципальных образований и обеспечение национальной безопасности Российской Федерации. Согласно направлениям, перечисленным в определении, в процессе стратегического планирования формируются документы:

- целеполагания - ежегодное послание Президента РФ Федеральному Собранию, стратегия социально-экономического развития РФ, стратегия национальной безопасности РФ, стратегия научно-технологического развития РФ и др.;

- планирования и программирования - основные направления деятельности Правительства РФ, государственные программы РФ; государственная программа вооружения, схемы территориального планирования РФ, планы деятельности федеральных органов исполнительной власти;

- прогнозирования - прогноз научно-технологического развития РФ, стратегический про- 
гноз РФ, прогнозы социально-экономического развития РФ на долгосрочный и на среднесрочный периоды, бюджетный прогноз РФ на долгосрочный период.

Все перечисленные типы документов между собой тесно связаны и оказывают взаимное влияние друг на друга. В документах целеполагания определяются направления, цели и приоритеты социально-экономического развития. Плановые u программные документы содержат комплексы задач и конкретных мероприятий, направленных на достижение целей и приоритетов социально-экономического развития, обозначенных в рамках целеполагания. А документы прогнозирования позволяют составить научно обоснованное представление о рисках, направлениях, показателях и результатах реализации намеченных планов и программ. Однако, очевидно, что любые планы и программы можно рассматривать только в качестве «декларации о намерениях», если на их осуществление не будут выделены финансовые ресурсы, объемы которых утверждены и подлежат исполнению в обязательном порядке в соответствии с законом о бюджете. Поэтому для реализации стратегических приоритетов развития исключительную важность имеют программно-целевые методы бюджетного планирования, позволяющие «при- вязать» каждый бюджетный рубль к достижению конкретного результата. Взаимосвязь документов стратегического и бюджетного планирования федерального уровня представлена на рисунке 1.

Ежегодное послание Президента РФ Федеральному Собранию РФ является ключевым документом целеполагания, обеспечивающим координацию государственного стратегического управления и бюджетной политики в меняющихся условиях. В зависимости от рисков, возникающих в результате изменения внутренних и внешних факторов, в нем обозначается необходимость актуализации намеченных в документах долгосрочного и среднесрочного планирования стратегических целей и приоритетов обеспечения национальной безопасности.

В стратегических документах, принимаемых Правительством РФ в соответствии с основными направлениями своей деятельности [1], предусматриваются важнейшие цели и задачи государственной политики регулирования социально-экономических процессов по обеспечению устойчивого развития российской экономики и созданию на этой основе условий для повышения уровня жизни населения во взаимосвязи с инструментами по их достижению. Особое место в ряду таких документов занимает Концепция

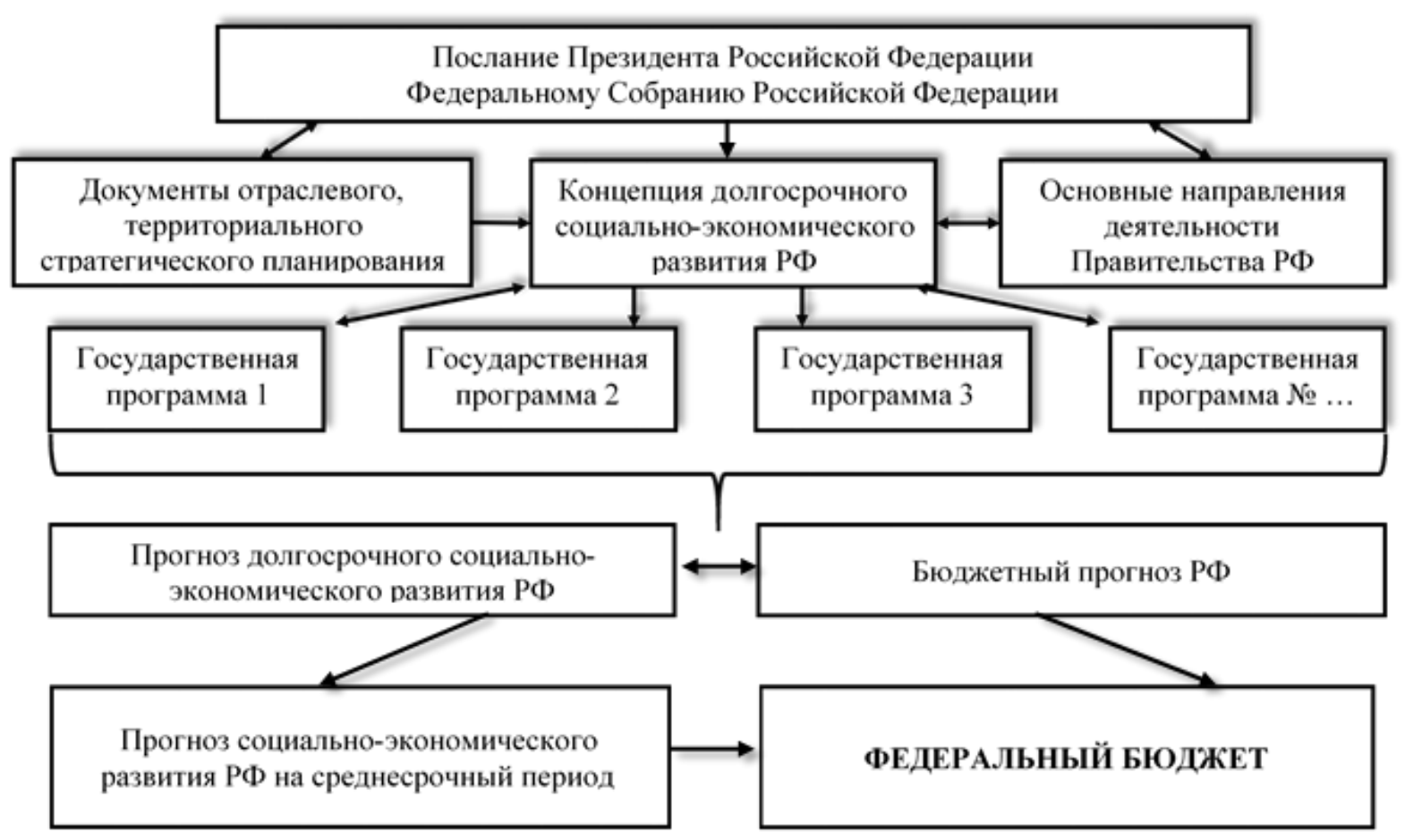

Puc. 1. Взаимосвязь документов стратегического планирования и прогнозирования с бюджетным планированием 
долгосрочного социально-экономического развития Российской Федерациии [2], которая определяет не только стратегические цели и приоритеты социально-экономического развития Российской Федерации, но и пути, способы и средства решения поставленных задач. Руководствуясь положениями Концепции, органы исполнительной власти разрабатывают государственные программы - документы стратегического планирования, содержащие комплекс планируемых мероприятий, взаимоувязанных по задачам, срокам осуществления, исполнителям и ресурсам, и инструментов государственной политики, обеспечивающих в рамках реализации ключевых государственных функций достижение приоритетов и целей государственной политики в сфере социально-экономического развития и обеспечения национальной безопасности Российской Федерации» [3].

В соответствии с Бюджетным кодексом РФ государственные программы являются основой формирования бюджета и их назначение как инструмента достижения целей стратегического планирования реализуется через «программный формат» среднесрочного (на трехлетний период) бюджетного планирования.

Содержание бюджетного планирования можно определить как целенаправленную деятельность наделенных соответствующими полномочиями органов государственной власти и управления по установлению достоверных количественных значений доходов и расходов публично-правовых образований на определенный период времени. В соответствии с приведенным содержанием его важнейшей функцией является обеспечение сбалансированности и устойчивости бюджетной системы, как основной предпосылки для реализации целей экономического роста и социального развития, декларируемых в стратегических документах целеполагания, планирования и программирования и конкретизируемых в Основных направлениях деятельности Правительства РФ. Реализация указанной функции осуществляется при помощи бюджетных планов органов власти, в которых расходы сбалансированы с суммарным объемом доходов и поступлений из источников финансирования дефицита бюджета.

Утверждение в форме закона конкретных значений доходов и расходов бюджетного плана позволяет государству решать задачи стратегического развития во всех секторах экономики и социальной сферы, сглаживая «провалы рынка», выравнивая неравенство в развитии отдельных отраслей, территорий и в распределении доходов между различными группами населения. Планируя бюджетные ассигнования на реализацию определённых механизмов взаимодействия государства и бизнеса, государство привлекает частный капитал к реализации крупных проектов в приоритетные отрасли экономики и в «депрессивные» регионы. Планируемые соотношения доходных и расходных параметров бюджета оказывают также непосредственное влияние на такие «изъяны» рынка, как инфляция и безработица. Иначе говоря, через параметры бюджетного плана государства, представляющего собой количественное выражение его финансовой политики, реализуется общественное назначение бюджета как встроенного регулятора экономики. Ориентиры финансовой политики, в свою очередь, задаются характеристиками состояния планируемого объекта в прошедшем периоде и научно-обоснованным прогнозом значений целевых показателей развития в экономике и социальной сфере, обозначенных в документах стратегического планирования.

Параметры бюджетного плана и заложенные в основу их расчета прогнозные значения основных макроэкономических показателей определяют экономическое поведение получателей средств бюджета, субъектов рынка и даже населения. С этой точки зрения особенно важен долгосрочный горизонт бюджетного планирования в «программном формате», как инструмента целевого управления, обеспечивающего прозрачность и предсказуемость решений государства.

Документом долгосрочного бюджетного планирования публично-правового образования, который позволяет синхронизировать цели государственных программ с объемами финансовых ресурсов, выделяемых на их достижение, и решать задачи обеспечения сбалансированности бюджета в долгосрочном периоде, является Бюджетный прогноз. Разрабатывается Бюджетный прогноз на основе сценарных условий функционирования экономики и основных параметров Прогноза долгосрочного социально-экономического развития РФ.

Бюджетный кодекс РФ (ст. 170.1) регламентирует основные составные элементы Бюджетного прогноза: прогноз основных характеристик соответствующих бюджетов, объемы 
финансового обеспечения государственных (муниципальных) программ на период их действия, основные подходы к формированию бюджетной политики на долгосрочный период, а также иные показатели. Конкретный порядок разработки, период действия, а также требования к составу и содержанию Бюджетного прогноза публично-правового образования устанавливаются соответствующим высшим исполнительным органом государственной власти (местной администрацией) [4].

Утверждение в Бюджетном прогнозе долгосрочных тенденций изменения объемов доходов и предельных размеров («потолков») расходов, в том числе по государственным программам, обеспечивает предсказуемость и позволяет устанавливать цели и показатели результатов, достижимые в рамках имеющихся объемов финансовых ресурсов. Наряду с другими документами, в соответствии со ст. 172 БК РФ, он составляет основу формирования бюджета публично-правового образования на трехлетний период (на муниципальном уровне, в определенных случаях,- на один год).

Таким образом важнейшие цели развития российской экономики и повышения уровня жизни населения обозначаются в ряде стратегических документов, принимаемых Правительством РФ [2, 5]. Ключевым инструментом, обеспечивающим согласование стратегического и бюджетного планирования, являются государственные программы. Бюджетный прогноз, определяющий объемы финансирования государственных программ в долгосрочном периоде, и среднесрочный (трехлетний) программный бюджет, который формируется в рамках бюджетного прогноза, призваны обеспечивать взаимосвязь целей, результатов и бюджетных средств, направляемых на реализацию приоритетов социально-экономического развития.

Как способ согласования целей стратегического управления и мер в области финансовой политики в современную практику бюджетного планирования внедряется программно-целевой метод, суть которого состоит в планировании расходов бюджета в разрезе государственных программ, содержащих четкую формулировку целей во взаимосвязи со способами и финансовыми ресурсами для их достижения.

Необходимость внедрения в практику нового инструмента программно-целевого бюджетирования - государственной (муниципаль- ной) программы и перехода на преимущественно программное планирование бюджетных расходов была обозначена впервые в 2010 году [6]. Убедительным аргументом такого решения была слабая «встроенность» в бюджетный процесс и в силу этого низкая эффективность целевых программ, имевших на тот момент практику применения.

Импульс к активизации усилий Правительства РФ к внедрению в практику бюджетного процесса государственных программ был придан Президентом РФ, который в своем Бюджетном послании Федеральному собранию «О бюджетной политике в 2014-2016 годах» подчеркнул, что: «Основным инструментом достижения целей государственной политики должны стать государственные программы, требования к которым будут вытекать из документов стратегического планирования, а механизмы и объемы их финансового обеспечения устанавливаться в долгосрочной бюджетной стратегии, трехлетних бюджетах и Программе повышения эффективности управления общественными (государственными и муниципальными) финансами на период до 2018 года».

Принципиально важным в новом представлении программного планирования является то, что государственная программа, в отличие от прежних целевых программ, представляет собой систему, взаимоувязанных по задачам, срокам осуществления и ресурсам, мероприятий и инструментов государственной политики, обеспечивающих в рамках реализации ключевых государственных функций достижение приоритетов и целей государственной политики в сфере социально-экономического развития и безопасности [7]. По каждой государственной программе ежегодно проводится оценка эффективности ее реализации, по результатам которой принимается решение о прекращении или изменении программы. Одним из основных критериев оценки эффективности реализации программы является достижение установленных в ней количественных показателей результативности целевых индикаторов.

Важнейшим условием эффективности государственной программы наряду с обоснованными механизмами ее реализации и корректным определением целевых индикаторов является наличие точно просчитанного бюджетного обеспечения. Именно поэтому возникает необходимость формирования бюджета на базе госу- 
дарственных программ, то есть в программном формате.

Вопросы программного формирования бюджетов на основе государственных (муниципальных) программ законодательно закрепил Бюджетный кодекс РФ в 2013 году [8]. Бюджетом, впервые сформированным в программном формате, стал федеральный бюджет на 2014-2016 годы. Его расходы были основаны на 40 государственных программах, сгруппированных по пяти приоритетным направлениям деятельности Правительства РФ.

С учетом утверждения в 2018 году государственной программы «Обеспечение обороноспособности страны» доля открытой части программных расходов федерального бюджета в 2018-2021 годах составляет от почти 65\% до немногим более 70\%. После принятия сформированной в аналитических целях, но еще не утвержденной государственной программы «Развитие пенсионной системы Российской Федерации», расходы, непосредственно увязанные с целями и результатами государственной по- литики, превысят 90\% расходов федерального бюджета (таблица 1).

Государственные программы, интегрирующие все инструменты реализации государственной политики, направленные на достижение поставленных целей и обеспечивающие согласование стратегического и бюджетного планирования, призваны стать ключевым механизмом государственного финансового регулирования социально-экономического развития. Однако, как показывает сложившаяся практика, реализации такого назначения государственных программ и программного бюджета препятствуют существенные ограничения:

- цели, задачи и показатели госпрограмм недостаточно увязаны с заявленными Правительством РФ стратегическими приоритетами развития;

- затруднена корреляция содержащихся в государственных программах целей, задач и показателей;

- в большинстве государственных программ отсутствует информация о взаимосвязи

Таблица 1. Структура расходов федерального бюджета в 2018-2021 годах в разрезе программных и непрограммных направлений деятельности, млрд. рублей

\begin{tabular}{|c|c|c|c|c|c|c|c|c|}
\hline \multirow[b]{2}{*}{$\begin{array}{c}\text { Направления реали- } \\
\text { зации }\end{array}$} & \multicolumn{2}{|c|}{2018 год } & \multicolumn{2}{|c|}{2019 год } & \multicolumn{2}{|c|}{2020 год } & \multicolumn{2}{|c|}{2021 год } \\
\hline & 362-Ф3 & $\begin{array}{c}\% \text { к } \\
\text { итого } \\
\text { расходов }\end{array}$ & Проект & $\begin{array}{c}\text { \% к } \\
\text { итого } \\
\text { расходов }\end{array}$ & Проект & $\begin{array}{c}\text { \% к } \\
\text { итого } \\
\text { расходов }\end{array}$ & Проект & $\begin{array}{c}\% \text { к } \\
\text { итого } \\
\text { расходов }\end{array}$ \\
\hline $\begin{array}{l}\text { Всего на государ- } \\
\text { ственные программы } \\
\text { (открытая часть) }\end{array}$ & 8354142 & 64,9 & 10488883 & 69,9 & 10982679 & 70,7 & 11199086 & 70,4 \\
\hline $\begin{array}{l}\text { в том числе по направ- } \\
\text { лениям: }\end{array}$ & & & & & & & & \\
\hline $\begin{array}{l}\text { I. Новое качество жиз- } \\
\text { ни (12 программ) }\end{array}$ & 3414174 & 26,5 & 3456500 & 23,0 & 3754286 & 24,2 & 3760286 & 23,6 \\
\hline $\begin{array}{l}\text { II. Инновационное } \\
\text { развитие и модерни- } \\
\text { зация экономики (18 } \\
\text { программ) }\end{array}$ & 2217679 & 17,2 & 2754618 & 18,4 & 2892007 & 18,6 & 3006003 & 18,9 \\
\hline $\begin{array}{l}\text { III. Обеспечение наци- } \\
\text { ональной безопасно- } \\
\text { сти (2 программы) }\end{array}$ & 1622 & 0,0 & 1401238 & 9,3 & 1450680 & 9,3 & 1498854 & 9,4 \\
\hline $\begin{array}{l}\text { IV. Сбалансированное } \\
\text { региональное разви- } \\
\text { тие (6 программ) }\end{array}$ & 1105092 & 8,6 & 1180336 & 7,9 & 1146675 & 7,4 & 1059340 & 6,7 \\
\hline $\begin{array}{l}\text { V. Эффективное госу- } \\
\text { дарство (4 программы) }\end{array}$ & 1615575 & 12,6 & 1696191 & 11,3 & 1739031 & 11,2 & 1874603 & 11,8 \\
\hline $\begin{array}{l}\text { Непрограммные на- } \\
\text { правления деятельно- } \\
\text { сти (открытая часть) }\end{array}$ & 4508575 & 35,1 & 4508575 & 30,1 & 4551196 & 29,3 & 4710159 & 29,6 \\
\hline $\begin{array}{l}\text { Итого расходы бюдже- } \\
\text { та (открытая часть) }\end{array}$ & 12862717 & 100 & 14997459 & 100 & 15533875 & 100 & 15909246 & 100 \\
\hline Всего расходы бюджета & 17229300 & & 18037246 & & 18994250 & & 20026029 & \\
\hline
\end{tabular}

Источник: Составлено автором по информации Счетной палаты Российской Федерации [9] 
со смежными госпрограммами, и, соответственно, нет эффективной координации между ответственными исполнителями государственных программ и исполнителями в рамках одной программы;

- по некоторым госпрограммам отсутствует положительная динамика показателей несмотря на то, что растут финансовые показатели их обеспеченности;

- установлено избыточное количество трудно администрируемых целевых индикаторов, что противоречит принципам необходимости и достаточности для достижения целей и решения задач госпрограмм.

В результате полноценная система программ, позволяющая с помощью комплекса взаимосвязанных мероприятий и межотраслевого взаимодействия достигать поставленные цели и решать намеченные стратегические задачи, пока еще не сформирована [10].

В целях преодоления ограничений действующей системы функционирования госпрограмм Правительство РФ внедряет принциилы проектного управления, позволяющие концентрировать ресурсы на ключевых задачах развития в рамках государственных программ [11]. В этом контексте начата работа по реализации приоритетных проектов (программ), которые являются структурными элементами государственных программ и, в то же время, обладают рядом существенных особенностей [12].

- наличие индивидуального для каждого проекта набора конкретных измеримых целей;

- концентрация усилий и бюджетных ассигнований на тех мероприятиях государственных программ, которые обеспечивают максимальный вклад в достижение ключевых приоритетов государственной политики;

- ускоренный порядок принятия управленческих решений благодаря участию руководства Правительства РФ и соответствующих органов исполнительной власти в управлении проектами.

В 2017 году были одобрены направления стратегического развития и в их рамках утверждены паспорта 22 приоритетных проектов, реализация которых должна была позволить максимально сконцентрировать финансовые, административные, управленческие ресурсы, усилить ответственность за решение поставленных задач, увеличить отдачу от использования финансовых ресурсов [13]. Однако, интеграция утвержденных приоритетных проектов в государственные программы, осуществленная в ходе бюджетного цикла на 2017 год и плановый период 2018 и 2019 годов, была в значительной степени формальной и не затронула действующие процедуры формирования и реализации госпрограмм.

В контексте дальнейшего развития методологии программного бюджетирования за счет расширения практики проектного управления Министерством финансов РФ ставятся следующие задачи [12]:

- повышение качества системы целеполагания госпрограмм: утверждение ограниченного перечня (3-5) наиболее приоритетных целей, характеризующихся общественной значимостью, амбициозностью, измеримостью и достижимостью;

- концентрация в составе госпрограмм всех расходов федерального бюджета, направленных на реализацию государственной политики в соответствующих сферах;

- обеспечение полноты учета в составе программ всех финансовых ресурсов и нефинансовых инструментов, способствующих достижению целей государственной политики в соответствующей сфере;

- обеспечение согласованности реализации мероприятий госпрограмм на федеральном и региональном уровнях;

- оптимизация формата госпрограмм и процедур их разработки, с учетом разграничения уровней ответственности и передачи значительных полномочий федеральным органам власти;

- уточнение структуры госпрограмм с выделением мероприятий проектного характера (ограниченные по срокам и приводящие к уникальному результату и/или качественному изменению процессов) и процессного характера (непрерывные или постоянно возобновляемые, реализуемые в соответствии с устоявшимися процедурами);

- управление проектными мероприятиями госпрограмм в соответствии с порядком организации проектной деятельности, в том числе с формированием соответствующих проектных комитетов и ведомственных координационных органов;

- организация управления процессными мероприятиями с использованием механизма ведомственных целевых программ, учитывая 
необходимость установления показателей результата для каждого процесса, а также необходимость повышения эффективности процессной деятельности;

- отказ от принятия новых и постепенное завершение реализации действующих федеральных целевых программ, как инструмента, не соответствующего единой логике проектного управления государственными программами.

Указом Президента Российской Федерации от 7.05.2018 г. № 204 определены национальные цели и стратегические задачи по осуществлению прорывного научно-технологического и социально-экономического развития Российской Федерации, увеличению численности населения, повышению уровня жизни граждан, созданию комфортных условий для их проживания, а также условий и возможностей для самореализации и раскрытия таланта каждого человека [14]. Для достижения поставленных целей разработаны 12 национальных проектов. Объемы их финансового обеспечения, выделяемые как дополнительный ресурс к базовым ассигнованиям федерального бюджета по государственным программам, приведены в таблице 2.
Для создания эффективной системы управления реализацией национальных и программных целей:

- национальные проекты интегрируются в действующие государственные программы путем их разделения на федеральные проекты с отражением бюджетных ассигнований на их реализацию на отдельных кодах Бюджетной классификации РФ;

- обеспечена увязка направлений расходов бюджета с измеримыми результатами федеральных проектов, входящих в состав национальных проектов;

- создан единый информационный ресурс, обеспечивающий регулярный мониторинг по всем уровням управления национальными (федеральными) проектами;

- установлена персональная ответственность за достижение целей, целевых показателей, решение задач, достижение результатов и контрольных точек, выполнение мероприятий проектов [15].

В рамках дальнейшего развития системы проектного управления проводится работа по следующим направлениям.

Таблица 2. Объемы финансового обеспечения реализации национальных проектов и комплексного плана модернизации и расширения магистральной инфраструктуры в 2019-2024 году, млрд. рублей

\begin{tabular}{|l|c|c|c|c|c|c|c|}
\hline \multicolumn{1}{|c|}{ Наименование } & $\mathbf{2 0 1 9}$ & $\mathbf{2 0 2 0}$ & $\mathbf{2 0 2 1}$ & $\mathbf{2 0 2 2}$ & $\mathbf{2 0 2 3}$ & $\mathbf{2 0 2 4}$ & $\mathbf{B c e г о ~}$ \\
\hline ВСЕГо & $\mathbf{1 6 8 5 , 5}$ & $\mathbf{1 8 6 2 , 7}$ & $\mathbf{2 0 8 4 , 8}$ & $\mathbf{2 5 1 2 , 5}$ & $\mathbf{2 4 5 2 , 8}$ & $\mathbf{2 3 4 1 , 3}$ & $\mathbf{1 3 0 3 2 , 0}$ \\
\hline в том числе: & & & & & & & \\
\hline Демография & 512,0 & 522,2 & 528,8 & 474,5 & 451,6 & 417,8 & 2906,8 \\
\hline Здравоохранение & 159,8 & 299,1 & 238,8 & 256,1 & 172,2 & 210,5 & 1336,5 \\
\hline Образование & 103,2 & 117,6 & 127,7 & 116,6 & 116,1 & 120,4 & 701,4 \\
\hline Жилье и городская среда & 105,3 & 105,3 & 108,4 & 172,8 & 172,4 & 212,0 & 876,2 \\
\hline Экология & 49,6 & 77,8 & 113,7 & 136,8 & 143,0 & 114,6 & 635,7 \\
\hline $\begin{array}{l}\text { Безопасные и качественные } \\
\text { автомобильные дороги }\end{array}$ & 129,7 & 104,3 & 137,4 & 23,9 & 23,2 & 22,5 & 440,9 \\
\hline $\begin{array}{l}\text { Производительность труда } \\
\text { и поддержка занятости }\end{array}$ & 7,1 & 6,9 & 6,9 & 7,4 & 7,1 & 8,3 & 43,7 \\
\hline Наука & 35,2 & 41,4 & 53,5 & 80,4 & 97,9 & 91,4 & 399,7 \\
\hline Цифровая экономика РФ & 107,9 & 128,7 & 177,9 & 258,3 & 217,0 & 218,9 & 1108,7 \\
\hline Культура & 12,7 & 13,6 & 16,7 & 19,9 & 21,0 & 16,1 & 100,0 \\
\hline $\begin{array}{l}\text { МСП и поддержка предпринима- } \\
\text { тельской инициативы }\end{array}$ & 57,3 & 32,5 & 46,8 & 94,9 & 91,4 & 72,6 & 395,4 \\
\hline $\begin{array}{l}\text { Международная кооперация и } \\
\text { экспорт }\end{array}$ & 82,5 & 70,4 & 119,6 & 186,3 & 229,8 & 202,2 & 890,9 \\
\hline $\begin{array}{l}\text { Комплексный план модерниза- } \\
\text { ции и расширения магистральной } \\
\text { инфраструктры }\end{array}$ & 323,2 & 343,0 & 408,6 & 684,7 & 710,2 & 634,1 & 3103,8 \\
\hline
\end{tabular}

Источник: Пояснительная записка «К проекту федерального закона «О федеральном бюджете на 2019 год и на плановый период 2020 и 2021 годов». Таблица 4.1 http://www.consultant.ru/cons/cgi/online.cgi?req=doc; base=PRJ; $\mathrm{n}=176750 \# 07724613267858516$ 
1. Обеспечение полной прослеживаемости движения бюджетных средств, направленных на реализацию национальных проектов.

2. Повышение эффективности взаимодействия между уровнями государственного управления и местного самоуправления, а также с государственными учреждениями.

3. В целях повышения оперативности право принятия решений о внесении изменений в распределение бюджетных ассигнований на реализацию национальных предоставляется проектным комитетам и кураторам соответствующих национальных проектов. При этом сохраняется механизм парламентского контроля.

4. Применение единых подходов подходов к разработке и реализации государственных программ, пилотных государственных программ и национальных проектов, перевод государственных программ на единые методологические принципы формирования, реализации и оценки их эффективности.

5. Совершенствование системы целеполагания государственных программ, оптимизация их структуры, а также развитие информационного ресурса, обеспечивающего процессы фор- мирования и мониторинга государственных программ [15].

Наряду с мерами по развитию проектного подхода в решении проблем экономики и социальной сферы, Правительство РФ уделяет немаловажное значение и необходимости повышения операционной эффективности «непроектных» направлений: «Несмотря на то, что ключевое значение в достижении обозначенных Президентом Российской Федерации целей будут иметь именно национальные проекты, то есть проектная составляющая государственных программ, важно обеспечить эффективность реализации всех текущих (процессных) мероприятий, без которых эти цели тоже не могут быть достигнуты» [16]. Таким образом, внедрение проектного подхода в программном формировании бюджетных расходов, наряду с иными мерами по совершенствованию программно-целевого бюджетного планирования, должно способствовать интеграции стратегического целеполагания, бюджетного планирования и операционного управления, создавая тем самым условия для обеспечения национальной безопасности страны.

\section{Библиографический список}

1. Основные направления деятельности Правительства Российской Федерации на период до 2018 года: утв. Правительством РФ 14.05.2015 № 2914П-П13.

2. О Концепции долгосрочного социально-экономического развития РФ на период до 2020 года: Распоряжение Правительства РФ от 17.11.2008 № 1662-р.

3. О стратегическом планировании в Российской Федерации: Федерального закона от 28 июня 2014 г. № $172-$ Ф3.

4. О бюджетном прогнозе Российской Федерации на долгосрочный период» (вместе с «Правилами разработки и утверждения бюджетного прогноза Российской Федерации на долгосрочный период: Постановление Правительства РФ от 31.08.2015 № 914

5. Стратегия национальной безопасности РФ до 2020 года: Указ Президента РФ от 12.05.2009 г. № 537.

6. Об утверждении Программы повышения эффективности бюджетных расходов до 2012 года: Распоряжение Правительства РФ от 30.07.2010 г. № 1101-p.

7. Об утверждении Порядка разработки, реализации и оценки эффективности государственных программ Российской Федерации: Постановление Правительства РФ от 02.08.2010 № 588

8. Бюджетный кодекс Российской Федерации: Федеральный закон от 31.07. 1998 г. № 145-ФЗ.

9. Заключение Счетной палаты Российской Федерации на проект федерального закона «О федеральном бюджете на 2019 год и на плановый период 2020 и 2021 годов» (утверждено Коллегией Счетной палаты Российской Федерации (протокол от 11.102018 г. № 50K (1271) // http://audit.gov.ru/upload/iblock/8b1/8b160ca6579 0d1ee123ad8c5f782011a.pdf

10. Заключение Счетной палаты Российской Федерации на проект федерального закона «О федеральном бюджете на 2018 год и на плановый период 2019 и 2020 годов» (утверждено Коллегией Счетной палаты Российской Федерации (протокол от 10 октября 2017 г. № 55K (1200): http://audit.gov.ru/activities/audit-of-thefederal-budget/31622/.

11. Об организации проектной деятельности в Правительстве Российской Федерации: Постановление Правительства РФ от 15.10.2016 № 1050 
12. Основные направления бюджетной, налоговой и таможенно-тарифной политики на 2018 год и на плановый период 2019 и 2020 годов (проект):// https://www.minfin.ru/ru/perfomance/budget/policy/\#ixzz5BtiC7Jga.

13. О решениях по итогам заседания президиума Совета при Президенте России по стратегическому развитию и приоритетным проектам 22.03.2017 г.: http://government.ru/orders/selection/401/27008/

14. О национальных целях и стратегических задачах развития Российской Федерации на период до 2024 года: Указ Президента Российской Федерации от 7.05.2018 г. № 204

15. Основные направления бюджетной, налоговой и таможенно-тарифной политики на 2020 год и на плановый период 2021 и 2022 годов // http://www.consultant.ru/document/cons_doc_LAW_334706/

16. Об утверждении Концепции повышения эффективности бюджетных расходов в 2019-2024 годах: Распоряжение Правительства РФ от 31.01.2019 № 117-р 